\title{
Pattern of acute poisoning in Al- Qassim region: a surveillance report from Saudi Arabia, 1999-2003
}

M. Moazzam, ${ }^{1}$ A.M. Al-Saigul, ${ }^{2}$ M. Naguib ${ }^{3}$ and M.A. Al Alfi

$$
\begin{aligned}
& \text { نمط التسمُّم الحاد في منطقة القصيم: تقرير ترصدي من المملكة العربية السعودية } 1999 \text { - } 2003
\end{aligned}
$$

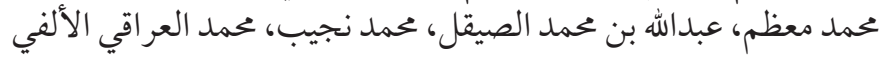

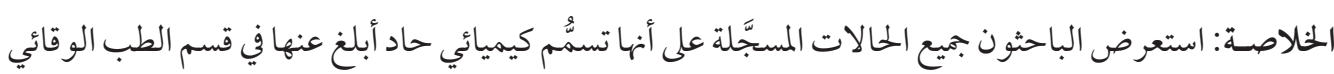

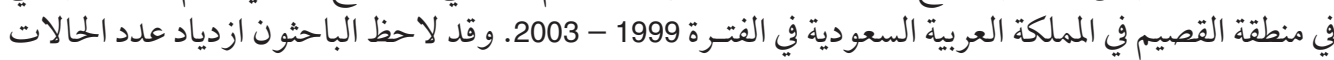

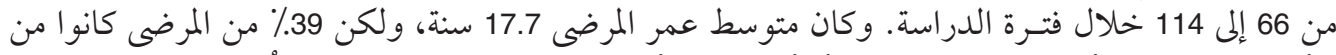

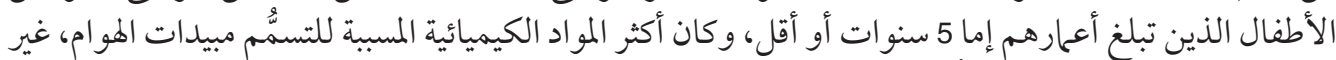

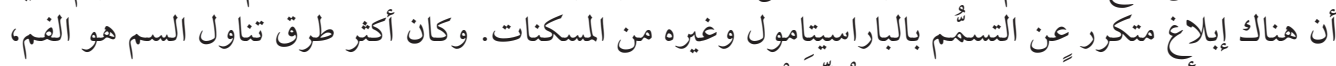

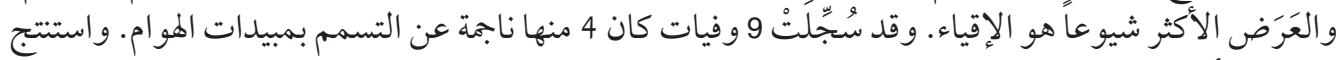

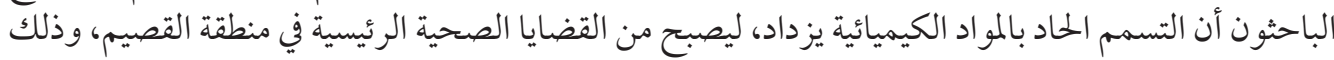

$$
\begin{aligned}
& \text { يتماشى مع الاتجاه العالمي. }
\end{aligned}
$$

ABSTRACT We reviewed all registered cases of acute chemical poisoning reporting to the preventive medicine department in the Qassim Region of Saudi Arabia from 1999 to 2003 . The number of cases increased from 66 to 114 during the study period. Mean age of patients was 17.7 years, and over $39 \%$ were children aged $\leq 5$ years. Pesticides were the most common chemical involved; paracetamol and other analgesics were also frequently reported. The oral route was the most frequent, while vomiting was the commonest symptom. Nine deaths were recorded, of which 4 were due to pesticide poisoning. In line with the global trend, acute chemical poisoning is growing as a major health issue in the Qassim Region.

Évolution des intoxications aiguës dans la région d'Al-Qassim : rapport de surveillance en Arabie Saoudite, 1999-2003

RÉSUMÉ Nous avons passé en revue tous les cas d'intoxication chimique aiguë enregistrés et déclarés au service de médecine préventive de la région d'Al-Qassim (Arabie saoudite) de 1999 à 2003. Le nombre de cas est passé de 66 à 114 pendant la période d'étude. L'âge moyen des patients était de 17,7 ans et plus de $39 \%$ étaient âgés de 5 ans ou moins. Les pesticides étaient les produits chimiques les plus souvent en cause; le paracétamol et les autres analgésiques étaient eux aussi souvent signalés. La voie orale était la plus fréquente et le vomissement était le symptôme le plus courant. Neuf décès ont été enregistrés, dont quatre étaient dus à une intoxication par les pesticides. Conformément à la tendance mondiale, l'intoxication chimique aiguë est un problème sanitaire grandissant dans la région de Qassim.

\footnotetext{
${ }^{1}$ World Health Organization Country Office, Islamabad, Pakistan (Correspondence to M. Moazzam: dmoazzam@hotmail.com; moazzamm@whopak.org

${ }^{2}$ Primary Health Care Administration; ${ }^{3}$ Department of Preventive Medicine, General Directorate of Health, Al-Qassim, Saudi Arabia.

Received: 01/11/06; accepted: 12/04/07
}

المجلة الصحية لشرق المتوسط، منظمة الصحة العالمية، المجلد الخنامس عشر، العدد ع، 9 +. 


\section{Introduction}

Acute chemical poisoning is a major public health concern. The World Health Organization estimates that total number of acute unintentional poisonings throughout the world ranges from 3.5-5.0 million cases annually, of which 3 million are severe poisonings resulting in 20000 deaths annually, while the estimated annual intentional poisonings number 2 million resulting in 200000 suicides $[1,2]$.

Exposure to chemicals can be accidental or iatrogenic in young children, whereas it is usually deliberate among adults [3]. The increased tendency to use over-the-counter drugs has resulted in a significant rise in the numbers of patients admitted to hospital suffering from overdose [4].

Acute chemical poisoning being a major public health issue formed the rationale for undertaking this study to estimate the acute chemical poisoning situation in Qassim, Saudi Arabia in relation to national and international experience.

The specific objectives of the study were to describe the magnitude and characteristics of chemical poisoning in the Qassim region and to formulate recommendations to: a) improve chemical poisoning surveillance in the region and b) suggest interventional programs to minimize chemical poisoning.

\section{Methods}

This was a retrospective study of all registered cases of acute chemical poisoning at Preventive Medicine Department, Qassim Region, Saudi Arabia for the period April 1999-February 2003.

The total population of the region during the year 2000 was close to a million (979 858) [5]. The population for other years was adjusted using a growth rate of $2.9 \%$ [6]. Surveillance data in Qassim
Region, Saudi Arabia was reviewed by the authors during the period from April 2004-September 2004. The cases were reported by hospitals and related health facilities under the administrative control and standardized forms of the Ministry of Health. Cases were defined as any person at any age with symptoms after history of exposure to chemical material or medicines in excess of their therapeutic limits. Data for patients, illnesses, and chemical material characteristics were analysed using EpiInfo, version 6.04.

\section{Results}

During the period April 1999-February 2003, the total reported number of cases of acute chemical poisoning in Qassim region was 404 . Table 1 shows the annual rise in cases since the year 2000 from 66 to 114 cases, with an estimated annual incidence of 10.7 cases per 100000 population in the year 2003.

The total population of Qassim region in 2000 was recorded as 979858 . Buraidah is the main city in the region with about onethird of the population residing there. More than half the reported cases, 235 (58.2\%), were from Buraidah district. Most cases $(116,28.7 \%)$ were reported from Buraidah Central Hospital followed by the Maternity

\begin{tabular}{lcc}
\hline $\begin{array}{l}\text { Table 1 Yearly distribution and incidence of } \\
\text { poisoning in Qassim region, 1999-2003 ( } \boldsymbol{n} \\
\text { = 404) }\end{array}$ \\
\hline Year & No. of cases & $\begin{array}{c}\text { Annual } \\
\text { incidence }\end{array}$ \\
\hline 1999 & 66 & 6.9 \\
2000 & 48 & 4.9 \\
2001 & 76 & 7.5 \\
2002 & 100 & 9.6 \\
2003 & 114 & 10.7 \\
\hline
\end{tabular}

${ }^{a}$ Cases/100 000 population. 
and Children's Hospital Buraidah, which reported $113(28.0 \%)$ cases.

Table 2 shows patient characteristics. Most cases were Saudi Arabians (310, $76.7 \%)$ and just over half were males (229, $56.7 \%$ ). Mean ages was 17.7 years (range $0.5-86$ years); $39 \%$ were $\leq 5$ years of age. Vomiting was the most common presenting symptom $(203,50.2 \%)$. The mean time of appearance of symptoms after ingestion was 2.3 hours, range $0.5-18$ hours; in 236 (58.4\%) cases, however, symptoms appeared within 1 hour.

Nine patients died, giving a mortality rate of $2.2 \%$; all other 395 reported cases $(97.8 \%)$ recovered with no reported sequelae.

Chemicals were responsible for 234 $(57.9 \%)$ cases (Table 3$)$, whereas 170 (42.1\%) cases were due to use of medicines outside therapeutic limits and advice. Pesticides were involved in $100(24.7 \%)$ cases and were the main chemical agent causing death. The most common recorded route was ingestion; 315 (78.0\%), whereas liquid

Table 2 Patient characteristics for cases of acute chemical poisoning in Qassim region, 1999-2003 $(n=404)$

\begin{tabular}{lrc}
\hline Variable & No. & $\%$ \\
\hline Age group (years) & & \\
$0-15$ & 189 & 47 \\
$>15$ & 215 & 55 \\
Males & 229 & 57 \\
Saudi Arabians & 310 & 77 \\
Common symptoms & & \\
$\quad$ Vomiting & 203 & 50 \\
Dizziness & 129 & 32 \\
Difficulty breathing & 88 & 21 \\
Irritability & 73 & 18 \\
Constricted pupils & 70 & 17 \\
$\quad$ Unconscious & 68 & 16 \\
Headache & 62 & 15 \\
$\quad$ Mortality & 9 & 2.2 \\
\hline
\end{tabular}

Table 3 Acute poisoning, characteristics of materials, Qassim region, 1999-2003 (n = 404)

\begin{tabular}{lrr}
\hline Variable & No. & \multicolumn{1}{c}{$\%$} \\
\hline Chemical $^{\text {Pesticide }}$ & 234 & 57.9 \\
Kerosene oil $^{\text {a }}$ & 100 & 24.7 \\
Household bleach & 29 & 7.2 \\
Carbon monoxide & 23 & 5.7 \\
Acid & 22 & 5.4 \\
Thinner/diesel oil & 11 & 2.7 \\
Other & 11 & 2.7 \\
Medications & 37 & 9.4 \\
Paracetamol \& other & 170 & 42.1 \\
$\quad$ analgesics & & \\
CNS-acting & 41 & 10.1 \\
Antihistamines & 41 & 10.1 \\
Multiple drugs & 18 & 4.6 \\
Oral contraceptive pills & 16 & 4.0 \\
Other & 7 & 1.7 \\
Physical form & 47 & 11.6 \\
$\quad$ Liquid & & \\
$\quad$ Solid & 176 & 43.6 \\
$\quad$ Gas & 150 & 37.1 \\
$\quad$ Other & 38 & 9.4 \\
Route of administration & 40 & 9.9 \\
Oral & & \\
Respiratory & 315 & 78.0 \\
Dermal & 47 & 11.6 \\
Other & 21 & 5.2 \\
\hline Orgaphosphates & 6 & 1.4 \\
\hline
\end{tabular}

${ }^{a}$ Organophosphates + others: organousphorous pesticides form the main proportion (22\%).

${ }^{b} \mathrm{CNS}=$ central nervous system: benzodiazepine, antipsychotics, antidepressants, alcohol, etc.

"Powders, creams and "not recorded".

and solid forms were the most common physical forms reported $176(43.6 \%)$ and 150 cases $(37.1 \%)$ respectively.

All cases in children $\leq 5$ years (159) were accidental poisoning (Table 4). In total, $247(61.1 \%)$ were accidental. Intentional poisoning was reported in 109 cases $(27.0 \%)$, with a male to female ratio of $2: 3$. Occupational poisoning occurred in 28 cases $(6.9 \%)$. 


\begin{tabular}{|c|c|c|c|c|c|c|c|c|}
\hline \multirow[t]{2}{*}{ Age (years) } & \multicolumn{2}{|c|}{ Accidental } & \multicolumn{2}{|c|}{ Intentional } & \multicolumn{2}{|c|}{ Occupational } & \multicolumn{2}{|c|}{ Unknown } \\
\hline & No. & $\%$ & No. & $\%$ & No. & $\%$ & No. & $\%$ \\
\hline$\leq 5$ & 159 & 39.5 & 0 & 0.0 & 0 & 0.0 & 0 & 0.0 \\
\hline $6-15$ & 26 & 6.4 & 4 & 1.0 & 0 & 0.0 & 0 & 0.0 \\
\hline $16-25$ & 24 & 5.9 & 55 & 13.6 & 5 & 1.2 & 10 & 2.4 \\
\hline $26-35$ & 20 & 4.9 & 33 & 8.2 & 17 & 4.3 & 4 & 1.0 \\
\hline $36-45$ & 8 & 2.0 & 13 & 3.2 & 5 & 1.2 & 4 & 1.0 \\
\hline$>45$ & 10 & 2.5 & 4 & 1.0 & 1 & 0.2 & 2 & 0.5 \\
\hline Total & 247 & 61.2 & 109 & 27.0 & 28 & 6.9 & 20 & 4.9 \\
\hline
\end{tabular}

\section{Discussion}

The surveillance data had a few known shortcomings: the present surveillance system (including reporting of acute poisoning) started in 1995 (replacing the previous system) and under-consultation by patients or their proxy and under-reporting by health institutes are the main reasons for weak chemical poisoning surveillance. However, much can be learnt from the simple results obtained. The number of reported cases and the estimated incidence $(10.7 / 100000$ population) indicate there is a problem that deserves continuous assessment and interpretation. Gradual strengthening and capacity-building of the information system for chemical poisoning is desirable. Given that this system is quite new, and more cases are being reported every year, the real number is expected to be much higher. Most reported cases came from large cities: more than half were from the capital of the region, Buraidah, where one third of the population resides. Surveillance is expected to better in the capital as patients are more likely to consult for minor symptoms (or even without symptoms) and health institutes do comply better with the reporting. Although the Maternity and Children's Hospital is the referral pediatric hospital for Qassim Region, acute cases are usually seen and stabilized, and hence reported, before being referred for advanced care at this hospital.This may support the notion of under-reporting from the smaller districts. Our estimated incidence is lower than that reported in a study conducted in the Eastern Province of Saudi Arabia [7] and in another in the north of Jordan [8].

The highest proportion of acute poisoning was observed among children $\leq 5$ years of age, which corresponds with the findings of similar studies conducted in other areas of Saudi Arabia [9-14] and other countries in the region [15-17]. The lowest proportion of poisoning was among people aged $>50$ years $(3.2 \%)$, is similar to another study from Jeddah [18].

Accidental poisoning was commonest amongst children for obvious, though highly preventable, reasons, mainly accidental exposure to household products and drugs. Small children especially remain a significant problem for this age group as shown in many other studies [19-21]. Interventions need to be designed to address this aspect. On the other hand, intentional poisoning is also quite frequently witnessed. Most intentional poisoning cases were among teenagers and young adults, with females significantly outnumbering males. Drugs were commonly the mode of intentional poisoning in our study consistent with the 
findings of other studies [7-8,21-23]. The proportion of occupational poisoning cases seen $(6.9 \%)$ was slightly higher than that reported by the Ministry of Health Central Department of Preventive Medicine (4.7\%) [14].

The commonest chemical substance cited was pesticides, in accordance with the findings of other studies $[16,19,24,25]$. Organophosphorus compounds (22\%) were the most commonly involved, both in accidental and occupational poisoning.

Chemical poisoning due to use of medicines outside their therapeutic limits and advice was more frequent than in an Australian study [26]. Paracetamol and other analgesics were the most common drugs cited among all age groups, in accordance with the results of other studies $[8,23]$ whereas drugs acting on the central nervous system were mainly used by adults in intentional poisoning, showing a distinct similarity with the results of another Saudi Arabian study [7].

The mean time between ingestion and appearance of symptoms was 2.3 hours and symptoms appeared within one hour in $58.4 \%$ cases, indicating the urgency of case management.

Overall mortality rate $(2.2 \%)$ is slightly higher than the study $(1.3 \%)$ conducted in the Islamic Republic of Iran [27], while the mortality rate among the age group $0-5$ years $(1.8 \%)$ coincides with other results from Saudi Arabia [28].

The oral route was the most common route of poisoning in our study in accordance with results of other studies in Saudi Arabia [18] and other countries [19,20,23]. Liquid was the most common physical form used, as found in a previous Saudi Arabian study [18].

\section{References}

1. Lawson GR, Craft AW, Jackson $R H$. Changing patterns of poisoning in children in Newcastle, 1974-1981. British medical journal, 1983, 37:291-5.

2. Walton WW. An evaluation of the Poisoning Prevention Packaging Act. Paediatrics, 1982, 69(3):363-70.

3. Sibert J, Davies PA. Poisoning, accidents and sudden infant death syndrome. In: Campbell AGM, Mclntosh M, eds. Forfar and Arneil's textbook of paediatrics, 4th ed. London, Churchill Livingstone, 1992:1777-800.

4. Tibballs J. Epidemiology of acute poisoning, Medicine international, 1989, 61:2496-8.

5. Annual report. Riyadh, Saudi Arabia, Ministry of Economy and Planning, 2000.

6. World Health Report 2002: reducing risks, promoting healthy life. Geneva, World Health Organization, 2003.
7. Daradkeh TK, Al-Zayer N. Parasuicide in an Arab industrial community: the Arabian-American Oil Company experience, Saudi Arabia. Acta psychiatrica scandanavica, 1988, 77(6):707-11

8. Saadeh AM et al. Deliberate self poisoning with drug and household products in North Jordan: a 4-year review. Saudi medical journal, 1995, 16(6):527-31.

9. Al Hifze IS, Kuman P, Talol W. Hospitalization due to acute poisoning in children, Tabouk experience. Journal of family and community medicine, 1995, 2:27-30.

10. Khalil AHA. Accidental poisoning in Saudi children seen at Riyadh Al-Kharj Military Hospital. Saudi medical journal, 1986, 7:613-7.

11. Al Hazmi M. Abed. Patterns of accidental poisoning in children in Jeddah, Saudi Arabia. Annals of Saudi medicine, 1998, 18(5):457-9.

المجلة الصحية لشرق المتوسط، منظمة الصحة العالمية، المجلد الخامس عشر، العدد ع، 9 . • 
12. El Mouzan MI, El Ageb A, Ali NK. Accidental poisoning of children in the eastern province. Saudi medical journal, 1986, 3:231-6.

13. Al-Sekait MA. Epidemiology of accidental poisoning of children in Riyadh, Saudi Arabia. Annals of Saudi medicine, 1990, 3:276-9.

14. Report on acute chemical poisoning among all regions of Saudi Arabia during first six months of year 1425 H (2004). Riyadh, Saudi Arabia, Ministry of Health, Central Department of Preventive Medicine, 2004.

15. Naji NA, Abdullah ZA. Kerosene poisoning in children in Iraq. Post-graduate medical journal, 1995, 71:419-2.

16. Al-Sharbati MM, El-Burghthy S, Sudani $\mathrm{OH}$. Accidental poisoning in children. Saudi medical journal, 1998, 19:423-8.

17. Dawod ST, Genelin RS, Asfoura EG. Accidental poisoning of children in Qatar. Annals of Saudi medicine, 1989, 9:243-6.

18. Ghaznawi HI, Gamal-Eldin H, Khalil AM. Poisoning problem in Jeddah Region. Annals of Saudi medicine, 1998, 18(5):460-2.

19. Yang $\mathrm{CC}$ et al. Children poisoning in Taiwan. Indian journal of pediatrics, 1997, 64(4):469-83.

20. Andiran N, Sarikayalar F. Pattern of acute poisonings in childhood in Ankara, what has changed in 20 years? Turkish journal of pediatrics, 2004, 46(2):147-52.
21. Abdollahi M et al. A retrospective study of poisoning in Tehran. Journal of clinical toxicology, 1997, 35(4):387-93.

22. Juárez-Aragón $\mathrm{G}$ et al. Características clinicas y epidemiológicas de intoxicaciones graves en una población adulta que ingresa a una unidad de cuidados intensivos [Clinical and epidemiological characteristics of severe poisoning in an adult population admitted to an intensive care unit]. Gaceta médica de México, 1999, 135(6):669-75.

23. Goksu $S$ et al. Characteristics of acute adult poisoning in Gaziantep. Journal of clinical toxicology, 2002, 40(7):833-7.

24. Yamamoto I et al. Prevalence of chemical poisoning and drug abuse in Japan. Japan. In: Annual report, Japanese National Research Institute of Police Science 1996. Japan, 1998.

25. Olson DK et al. Pesticide poisoning surveillance through regional poison control centers. American journal of public health, 1991, 81(6):750-3.

26. Tibballs J, McArdle EJ, Brown TCK. Drug overdose in children. Australian paediatric journal, 1985, 21(1):7-11.

27. Shadnia S et al. Pattern of acute poisoning in Tehran-Iran in 2003. Human \& experimental toxicology, 2007, 26(9):753-6.

28. White LE, Driggers DA, Wardinsky TD. Poisoning in childhood and adolescence: a study of 111 cases admitted to a military hospital. Journal of family practice, 1980 , 11(1):27-31. 